\title{
SANTAS E DÓCEIS OU INSUBMISSAS E DESGRAÇADAS? UMA ANÁLISE DE TRAJETÓRIAS DE MULHERES RESGATADAS DA ESCRAVIDÃO NA ÁFRICA CENTRAL NO CONTEXTO COLONIAL (1870-1945)
}

\author{
Patrícia Santos Schermann \\ Professora de História da África - Unifesp
}

\begin{abstract}
Resumo
Este artigo analisa as trajetórias das jovens resgatadas da escravidão pelas missões católicas na África central, no período de 1870 a 1945, no contexto da aproximação e conquista colonial britânica. Dentre essas resgatadas, destaca-se a figura de Josephina Bakhita, cuja trajetória como escrava no Sudão e como livre na Itália, a levou a ser canonizada em 2000 como a "grande Irmã Universal", que soube ser obediente aos seus superiores na vida como escrava e como liberta. Tal fato mostra como a análise da trajetória dela e de outras resgatadas é de fundamental importância para se compreender os mecanismos coloniais e pós coloniais de construção de práticas políticas e religiosas de subalternidade feminina.
\end{abstract}

\section{Pallavras-Chave}

Mulher • África • Combate à Escravidão • Ordem Colonial • Pós-Colonialismo

\section{Abstract}

The present paper analyses the life-trajectories of young females redeemed from slavery by Central Africa catholic missions, between 1870 and 1945, period of the British colonial approximation and conquest. Among these redeemed young ladies, Josephina Bakhita was a remarkable figure. Her lifetrajectory includes a period as a slave-woman in Sudan and as a freedwoman in Italy. As a consequence she had been canonized in 2000 with the designation of "giant Universal Sister" - who knew how to be obedient to her superiors both as slave and freed. This fact shows how the analysis of her and of the other redeemed women life-trajectories is of fundamental importance for the comprehension of the development of colonial and pos colonial mechanisms of political and religious practices of feminine subalternity.

\section{Keywords}

Woman $\bullet$ Africa $\bullet$ Opposition to Slavery $\bullet$ Colonial Order $\bullet$ Postcolonialism 
Em 2000, na Basílica de São Pedro, ganhava a glória dos altares através do Papa João Paulo II, Josephina Bakhita, religiosa da congregação das Canossianas, resgatada da escravidão, que passou a ser denominada como a "Grande Irmã Universal”. Naquele ano, acreditava-se exaltar não só a África, mas o papel da mulher cristã negra na ação catequética e missionária da Igreja. Bakhita, a santa da África contemporânea tinha uma imagem, que foi estampada nos principais periódicos católicos e na imprensa laica, jovial, serena e com um olhar profundo que convida a quem a vê a se condoer e a se unir a obra católica do século XXI de se "salvar a África pela África", ou seja, de promover vocações religiosas e laicas para se garantir o futuro do Cristianismo no continente. De acordo com um dos seus hagiógrafos, Roberto Zanini, a santa representa:

Para a África, Bakhita é a esperança de libertação. Para a relação com o mundo muçulmano, uma ponte do diálogo. Para a raça negra, um sinal do resgate da plena dignidade. Para todos os homens e mulheres, uma santa, isto é, uma irmã e um modelo na caminhada rumo a um mundo novo. ${ }^{1}$

Acreditava-se com isso também que a Igreja estaria, dentro dos vários discursos de reparação realizados pelo Papa João Paulo II, se reconciliando com as modernas nações africanas e se libertando da incômoda relação com o passado colonial do século XIX até o fim da Segunda Guerra Mundial e de pecados mais antigos, dentre os quais a omissão com relação à escravidão atlântica.

A Irmã Bakhita, sorella universale, iria reconciliar os cristãos de hoje da África com os antigos evangelizadores do passado, convidando ao perdão, a valorização da ação filantrópica e de combate à escravidão a despeito de ser no "alvorecer" do Colonialismo.

Com esse intento, publicou-se em várias línguas a Storia Meravogliosa, ou seja, a hagiografia de Ida Zanollini que popularizava para o mundo a figura da Sorella Moretta, como Bakhita foi conhecida pelos fiéis das paróquias de Schio. Além disso publicou-se revistas, histórias infantis baseadas nessa obra e no processo seu de beatificação e canonização.

${ }^{1}$ ZANINI, Roberto Ítalo. Bakhita: Mulher, negra, escrava e santa-uma fascinante história de liberdade. São Paulo: Cidade Nova, 2002. 
Assim, desenvolvia-se uma ação romana de uma possível valorização e de destaque do papel do cristianismo africano, de acordo com entrevistas dadas por bispos, conselheiros missionários, agentes pastorais por todo mundo.

A ação de se canonizar Bakhita fora encarada também por uma das suas biógrafas, Maria Luísa Dagnino, como uma forma de "dar a voz" para os que não a possuem . Além disso, também era tarefa da autora ressaltar como que a personagem soube utilizar e vivenciar como ninguém "o valor do silêncio":

10 de fevereiro de 1993. Outra surpresa - o Papa João Paulo II está na África para a sua décima visita apostólica. Quis concluí-la em grande estilo: enfrentando riscos ergueu corajosamente a voz em defesa dos sem voz. Expressou comovida admiração por todos os que perseveraram na fé e rejubilou-se com todos porque, no dia 10 de fevereiro de 1993, "Bakhita retornou a cãs" justamente na capital do Sudão, Cartum. A Madre Geral das Canossianas - M. Elide Testa entregou ao Papa um busto com o relicário da Beata Bakhita. Na imensa praça Verde da capital, um milhão de jubilosos sudaneses, juntamente comk o Santo Padre João Paulo II e ao acerbispo Gabriel Zubeir Waco, uniram suas vozes e corações para gritar: "Bakhita, welcome home!" - Bem Vinda a sua casa, Bakhita! ${ }^{2}$

Bakhita tornou-se, ao abdicar da sua voz em função da obediência, no discurso missionário e hagiográfico contemporâneo sobre ela, uma figura chave que justificava a ação evangelizadora contemporânea, sobretudo porque se enfatizou mais em todo processo de beatificação a sua origem "africana e servil", do que as consequiências da sua trajetória em Schio e sua interação com a comunidade local. Sua vida na Itália é encarada como uma passagem que se situa entre um início marcado pela "barbárie" da escravidão e do ambiente africano, e o final no paraíso celeste, como a "Grande Irmã Universal".

Seu lugar subalterno na vida religiosa e social determinou todo o rumo e o futuro da trajetória da personagem, possibilitando identificá-la como uma figura eternamente ligada ao continente, o que possibilitaria na construção da memória hagiográfica, a "possível volta para a casa"- a saber, o Sudão.

${ }^{2}$ DAGNINO, Maria Luísa. Bakhita da escravidão à liberdade. São Paulo, Edições Loyola, 1995. p. 102. 
Para Dagnino, o fato de estar indelevelmente marcada pela sua origem africana, a despeito das interações e transformações que sofrera na vida pessoal, possibilitava ao hagiógrafo acessar a essência da "sua natureza":

Da evidência dos fatos, pode se deduzir que Bakhita recebera da natureza um caráter dócil e manso, uma sensibilidade e delicadeza de sentimentos extraordinários - tinha uma forte propensão para amar e ser amada - tivera modo de gozar e padecer esta sua paixão tanto na família como depois, durante a sua vida de escrava. Apreciava o mínimo ato de bondade e de atenção afetuosa - quando lhe faltava, sofria intensamente.

(...) Muitos sublinharam a sua docilidade de caráter; essa porém, não a impediu de erguer-se decididamente contra as aliciantes promessas de uma vida mais fácil e na sua pátria, quando isso podia comprometer a sua fé católica.

Aquela que se considerava "como escrava, uma coisa de propriedade dos seus patrões", quando foi colocada diante da alternativa de escolher um bem imediato e já conhecido, não hesitou em optar pelo desconhecido, mas para ela , existencialmente mais seguro. Sabia unir à ternura do seu coração e à mansidão de natureza um discernimento claro e uma inabalável força de vontade. ${ }^{3}$

Suas "virtudes" a inseriam num lugar de pureza e de subalternidade que teriam transformado a sofrida existência, a partir do que se pode depreender da obra de Dagnino, na própria rememoração da Paixão de Cristo, para o bem maior da humanidade.

Sua ausência de ambição e a correção nos modos eram o exemplo vivo da dignificação das "funções simples", exercidas por aqueles que não tiveram acesso às possibilidades mais amplas de educação e inserção social tal dimensão se remete profundamente à visão da Rerum Novarum, escrita há mais ou menos 130 anos, a respeito do bom governo e da liderança cristã sobre o operário e os demais trabalhadores subalternos. "Servir nas pequenas coisas" era a medida da grandeza das almas, na visão teológica de Leão XIII sobre o trabalhador, que se consubstancia com a valorização do papel do trabalhador doméstico e

${ }^{3}$ DAGNINO, Maria Luísa, Op cit, p. 67-68. 
da sua educação para o mundo moderno, na perspectiva cristã do Pós Segunda Guerra Mundial. ${ }^{4}$

Foi dentro dessa visão mais ampla a respeito de Bakhita e do trabalhador doméstico, que sua canonização fora proclamada e apontada como o início de uma valorização de demais exemplos africanos de fidelidade ao Cristianismo.

No entanto, algo pesava sobre esse conjunto de iniciativas da Santa Sé que gerava um incômodo tão grande quanto o do "não reconhecimento" de possíveis santidades da África: ao mesmo tempo em que havia um investimento para que através de Bakhita, a África tivesse a hora e vez nos corações e mentes dos católicos - esse incômodo veio, de início pela própria reação da imprensa laica que questionava o que de heróico havia feito a personagem? O que havia de sobrenatural em sua vida que justificava essa canonização? No ano de 2003, o Jornal La Repubblica de Roma, perguntava o que a santa africana e outras figuras canonizadas por João Paulo II poderiam trazer de novo, uma vez que não havia nada de "surpreendente" em suas vidas?

As respostas, em contrapartida, enfatizavam as dores de Bakhita, o fato de ter sobrevivido aos sofrimentos do cativeiro e principalmente, por trazer em si, de forma "inata", a religião "natural".

Perceber tais respostas no ano de 2003, me levaram a ver o que esta personagem significava realmente para os setores ligados à moderna evangelização dos povos, o que de fato era tão perceptível para seus postuladores que não era para nós, laicos, que vivenciamos a Guerra Fria, as lutas pela libertação da África e da Ásia, os protestos e lutas contra a ditadura na América Latina. Mergulhando no seu processo de canonização e nas publicações sobre essa personagem, emerge um dado fundamental para a compreensão não só das ações religiosas, mas creio que também das práticas filantrópicas contemporâneas, que é o do fascínio que existe pela fase das campanhas anti-escravistas na África no século XIX e o despontar de homens e mulheres não brancos que foram imortalizados pelas revistas missionárias como os resgatados da escravidão.

\footnotetext{
${ }^{4}$ Sobre o investimento na cristianização do trabalhador doméstico por parte da igreja, ver BUTTA, Nice Neves. A Casa da empregada doméstica. Monografia de conclusão de especialização em História do Brasil. Duque de Caxias, FEUDUC/ Dep. História, 2004, e sobre a subalternização das religiosas negras, muitas das quais instrutoras dos trabalhadores domésticos católicos, ver obras de Oscar Beozzo sobre o Vaticano II e a questão social na Igreja Católica.
} 
A história de Bakhita, na verdade, é um portal que acessa a um processo histórico importante para a elaboração de estatutos e códigos de indigenato na África, que é a da tutela sobre os ex-escravos, em especial das mulheres africanas salvas do cativeiro no século XIX até o final da Segunda Guerra Mundial.

Essas personagens ocuparam, a partir de 1870, ano significativo na medida em que se pode perceber o aumento da ação colonial européia, um lugar de destaque na literatura missionária e filantrópica. Suas desventuras eram relatadas em forma de confissões onde o leitor era convidado a participar da intimidade das suas dores, tendo a sensação de ser o único a poder decifrá-las, ao mesmo tempo em que a compartilhava com os outros. Era essa sedução com tom ao mesmo tempo intimista e público criava um vínculo salutar entre o cristão branco civilizado e o negro "nas trevas do paganismo", relação que era vista como benfazeja pelo Papa Leão XIII já no final do século XIX, que impedia o homem moderno na tensão entre a religião e o estado, ser indiferente a sorte dos mais "fracos". O difícil encargo do homem branco, de acordo com Kippling, ganhava uma profunda e significativa interpretação cristã, que condicionava a salvação das almas dos jovens das zonas rurais e das grandes cidades da Europa as das crianças das "regiões remotas" da África.

Na segunda metade do século XIX, pesava sobre as missões católicas e protestantes direcionadas para o antigo Vicariato Apostólico da África central, questões prementes, tais como, se seria possível o evangelho tornar-se nativo e se haveria a possibilidade das futuras comunidades cristãs ganharem uma autonomia, se bem que subalterna, de produzir importantes quadros missionários locais.

Destaca-se que a primeira pergunta que consistia em tornar o evangelho nativo, entendia como nativo uma categoria resultante da aproximação conceitual das definições de gentio, presentes nas experiências jesuíticas do primeiro missionarismo, datado dos séculos XVI ao XVIII, com as noções de raça e de hierarquia de populações que começaram a se gestar no início do processo colonial na África, a partir de 1870.

Portanto, poderia o evangelho ser um importante elemento civilizador que permitiria as missões católicas, na acepção de Comboni, ${ }^{5}$ serem as facilitadoras

\footnotetext{
${ }^{5}$ Antonio Daniele Comboni nasceu em Limone Sul Garda em 1831 e morreu em Khartoum (Sudão) em 1881. Foi Vigário Apostólico da África Central e fundador de dois importantes institutos missionários: o ramo masculino, denominado Istituto della Missioni per la Nigrizia (atuais Missionários Combonianos do Coração de Jesus) e o ramo feminino, denominado Pie Madri della Nigrizia (atuais Missionárias Combonianas do Coração de Jesus). VER: SANTOS, Patricia Teixeira. Dom Comboni: profeta da África e santo no Brasil. Rio de Janeiro: Mauad, 2002, p.111-154.
} 
do progresso dos povos africanos? Vários foram os exercícios para se responder a esta questão, tanto por parte dos padres católicos quanto por pastores. Contudo, um elemento que perpassava a todas essas respostas, era a ênfase na conquista espiritual e na disciplinarização do corpo feminino.

De acordo com Giorgio, ${ }^{6}$ na segunda metade do século XIX, percebe-se na Itália católica, um investimento catequético na mulher, de acordo com a visão da restauração do Catolicismo, que enfatizava o corpo feminino como "templo sagrado do Cristo doméstico" e a vida matrimonial, como o "calvário cotidiano", onde a mulher se uniria ao seu Salvador, suportando a tudo com força, docilidade, submissão e solicitude, para salvar não só a si, mas a todos os seus familiares.

Cristianizar o corpo da mulher era assegurar a vitória da fé, o estabelecimento da religião como norteadora da vida social, especialmente no contexto do processo de laicização dos Estados europeus ocidentais, ação que a Igreja Católica via como perniciosa, uma vez que relegava a esfera das suas ações ao domínio do privado. Conquistar a mulher, levá-la para auxiliar as atividades paroquiais, motivá-la a apoiar as ações missionárias nas terras dos "infiéis", fazê-las mães e madrinhas dos futuros sacerdotes, envolvendo-as na busca de recursos para a manutenção dos jovens seminaristas, correspondia a um conjunto de ações que repercutiam um grande efeito no social, mostrando que o Catolicismo ultramontano poderia interferir nos rumos do político, através da tropa de choque que eram as mulheres católicas.

Além disso, com a restrição ao ingresso masculino para a vida religiosa, em função do serviço obrigatório na França, na Itália e na Áustria, as mulheres religiosas ganharam um grande destaque na vida missionária, assumindo pólos missionários, sendo professoras e catequistas e cuidando do cotidiano das paróquias e das missões, assegurando com isso o êxito missionário católico na Ásia e na África.

${ }^{6}$ DI GIORGIO, Michela. Il modelo Cattolico: feminilità e controrivoluzione, in: PERROT, Michele \& DUBY, Georges (org). Storia delle donne in Occidente - l'ottocento. Bari: Laterza, 1991. 


\section{E a mulher na África, ou como, era conhecida nos periódicos missionários, a mulher nativa?}

A mulher africana aparece nos escritos missionários, ora como o exemplo da degradação da Maldição de Cam, ora como a esperança da "redenção" da África. Assim, Comboni aconselhava seus missionários a entrarem nos lares dos povos do Sudão, através das mulheres, das crianças e dos escravos, destacando de forma enfática, a importância da conversão das mulheres. Observador dos costumes islâmicos e dos povos do Nilo, o prelado percebia a importância econômica e social do trabalho feminino e não deixava de apontar para seus missionários que a conquista da alma da mulher nativa era a possibilidade de se construir o Cristanismo "doméstico", a pequena missão familiar, fato que contribuiria para o enraízamento do Catolicismo no continente, conquistando as terras do Islã "para Cristo".?

Num primeiro momento, acreditava-se que o investimento na catequese da mulher nativa, deveria ser feito através do incentivo da criação e formação de religiosas africanas. Essas, para que pudessem se contrapor, pela força do exemplo, à barbárie, precisariam, de acordo com os pressupostos do determinismo geográfico de Comboni, serem formadas fora da África, a fim de poderem se fortalecer e retornarem "civilizadas" e promotoras da fé cristã no continente. ${ }^{8}$

Nesse contexto, surge nos anos 70 do século XIX, uma importante figura para esse projeto missionário, a Irmã da Nigrizia Giuseppina Conde, jovem que assim como diversas meninas e meninos resgatados da escravidão, eram enviados para a Europa para viverem em orfanatos e estudarem em 'Escolas para meninos negros', a fim de retornarem, na fase adulta, como religiosas e religiosos nativos.

A exemplaridade da Irmã Giuseppina foi destacada por Comboni, no episódio em que narra o reencontro da jovem missionária com sua irmã de nascença que continuava imersa na "natureza selvagem" e "corrompida pelo Islamismo":

Alegro-me com o nosso reencontro" disse ( a irmã de Giuseppina), "mas me entristece vê-la cristã. Espero que se torne muçulmana como eu". "Não, querida, pelo contrário, espero que se torne cristã”, disse Giuseppina.”Eu

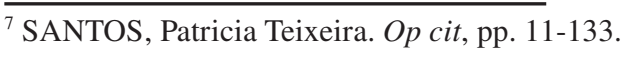


estive na Europa, passei muitos anos na Alemanha e lá me cobriram de benefícios e me fizeram conhecer o caminho que leva o Céu. Infundiramme o amor pela Santíssima Virgem e me tornaram cristã". A outra não aprovou as palavras da irmã, apesar de ter gostado de saber que Giuseppina esteve na Alemanha. No entanto, não queria que a irmã fosse cristã.

Giuseppina a convidou para me fazer uma visita, o que a outra refutou, por medo que eu a roubasse e a tornasse cristã. "Vem", disse Giuseppina, "vamos ao encontro do nosso pai, verá como ele é bom". Veio no outro dia, mas com muito medo. Desejava que eu permitisse que ela levasse a irmã para a sua casa, fato que eu refutei absolutamente. Pouco tempo depois, a irmã passou a visitar com freqüência Giuseppina e, por ora, parece muito disposta a se tornar cristã. ${ }^{9}$

Irmã Giuseppina era considerada também um símbolo do êxito da missão católica e da disciplinarização do corpo feminino no sentido de se constituir um Cristianismo de orientação ultramontana no coração da África.

Mas, ao mesmo tempo em que existia a figura de Giuseppina, Comboni também destaca o contraponto da selvageria e também de uma "nobreza de propósito" e de "sentimento" da mulher nativa, fato que motivaria a continuidade da tarefa missionária. Num relato feito às sociedades filantrópicas que o apoiavam, Comboni narra a história de três mulheres escravas de um comerciante austríaco que as tratava como concubinas. As mulheres teriam combinado entre si de seguirem as regras da poligamia, a partir do parâmetro religioso do Islã, a despeito do marido ser cristão e europeu e, assim, as duas esposas mais novas respeitavam as orientações da mais velha.

Com o falecimento do comerciante e os bens do mesmo sendo enviados para sua esposa cristã na Áustria, as três mulheres e os filhos reivindicaram o direito de terem parte do espólio, mas foi em vão, porque a situação das mesmas era considerada ilegal para o consulado austríaco em Khartum.

\footnotetext{
${ }^{8}$ SCHERMANN, Patricia Santos . Fé, Guerra e Escravidão: cristãos e muçulmanos face à Mahdiyya no Sudão ( 1881-1898). Tese de Doutorado. Niterói: Programa de Pós Graduação em História da UFF, 2005. Capítulo 02.

${ }^{9}$ COMBONI, D. Relazione allá Società di Colônia (Colônia-1871), apud, SANTOS, Patricia Teixiera, op cit, p. 131.
} 
Assim, de acordo com o prelado, as mulheres vagaram pelo deserto e se depararam com a missão católica onde pediram auxílio. Comboni teria dito a elas que receberiam ajuda, desde que se convertessem ao Catolicismo. As mulheres se enfureceram e chingaram e cuspiram nele e nos demais missionários que estavam próximo. Com isso, voltaram a vagar pelo deserto em busca de proteção. Como não tiveram êxito e, constrangidas pela doença e pela fome, além do medo de perderem as crianças, retornaram para a missão e pediram para ser batizadas, confiando a guarda das crianças aos missionários, para "fazerem deles sacerdotes". Pouco tempo depois, as mulheres faleceram e as crianças ficaram sob a tutela dos padres. ${ }^{10}$

Com esse relato, Comboni conclamou a atenção para dois fatores que considerava importantes para o êxito da implantação do Cristianismo - o primeiro, fruto da influência da idéia de perfectibilidade de Rosseau, pela qual o "bom selvagem" traria em si virtudes inatas que poderiam ser despertadas em momento de desafio e violência, mostrando a "nobreza natural" do ser humano, como no caso das três concubinas. O segundo, era a exortação e a necessidade do controle disciplinar do corpo do "homem branco" que se permitia, fora do seu ambiente doméstico, experimentar prazeres com as mulheres africanas, sujeitando-as e levando a perder o papel civilizador europeu.

Tal fato foi demonstrado por Comboni, quando orientou aos seus missionários a conviverem com a desconfiança do "outro". Ao referir-se aos "traficantes de escravos", eleitos os inimigos do progresso civilizatório e perpetuadores das "trevas", o prelado destacou:

Como os autores celerados destes horrendos delitos não pertencem, geralmente, a sua raça, mas são estrangeiros, aqueles desventurados selvagens habituaram-se a sempre serem traídos e maltratados das formas mais cruéis. Portanto, olham o missionário com desconfiança e temor, porque é estrangeiro. Por outro lado, os negros se manifestam aos olhos do mesmo como bárbaros, estúpidos, ingratos e brutais. Por isso, para poder estabelecer uma troca de afeto animadora, o missionário deve se resignar em ver a resistência hostil, as tristes infidelidades e as sombrias traições. ${ }^{11}$

\footnotetext{
${ }^{10}$ SCHERMANN, Patricia Santos, op cit., cap. 2.

${ }^{11}$ COMBONI, D. Regole dell'Istituto delle Missioni per la Nigrizia (1871), apud, SANTOS, Patricia Teixeira, op cit, p. 130.
} 
Diante da acentuação dos valores "inatos" existentes na humanidade da África, Comboni e os Padres de Nossa Senhora da África, instituto missionário fundado por Charles Martial Lavigerie, passaram a investir no resgate das mulheres da escravidão, conservando-as no continente, onde as mesmas, nas colônias anti-escravistas, deveriam ter o papel de "civilizar o território", contrapondo e superando econômica e socialmente as terras do Islã e as regiões "pagãs".

As colônias anti-escravistas, experiências desenvolvidas por institutos missionários e sociedades filantrópicas e de Estados europeus, tornaram-se algo recorrente no norte da África e na parte central do continente, a partir da década de 1870, por ocasião do acirramento do combate franco-britânico à escravidão e as disputas pelo controle da mão de obra liberada da escravidão.

Assim, na década de 70 do século XIX, Comboni escreve para a Propaganda Fide, a fim de justificar a criação da colônia anti-escravista de Malbes:

Para afastar, pois, esses neoconvertidos da peste e da sedução muçulmana, buscamos, obrigamo-nos ao gravíssimo sacrifício de fazer a compra de vastos terrenos na planíce de Malbes, que é abastecida suficientemente de água, além de fabricarmos casas e cabanas para instalar todos os mouros que foram convertidos no Instituto Masculino no Cordofan, e que possam se unir em matrimônio cristão com as mouras educadas no colégio das Irmãs. A cada família distribuímos um pedaço de terra para o cultivo de boa quantidade de grãos para semear, e assim possam viver independentemente e distantes da peste e da sedução muçulmana, sob a vigilância da missão católica e com o fruto do suor deles e com o auxílio das artes e ofícios que aprenderam na missão. Estas famílias católicas formarão, pouco a pouco, um vilarejo, um burgo católico que, com o passar dos anos, tornar-se-á uma cidade completamente católica, que será exemplo para as outras populações. ${ }^{12}$

Essa experiência, no caso do Sudão, foi interrompida pela vitória do movimento mahdista em 1881, liderado por Muhamamd Ahmad Ibn Allah, que obstacularizou a conquista britânica da região por um período de 17 anos,durando até 1898.

Nesses anos mahdistas, os catecúmenos e catecúmenas, originalmente resgatados da escravidão, foram dirigidos para Wadi Halfa no sul do Egito e

\footnotetext{
${ }^{12}$ COMBONI, D. Piccolo Rapporto sulla azione apostólica del Vicariato Apostólico dell' Africa centrale allá Pia Opera della Santa Infanzia di Parigi (Roma, 1877), apud, SANTOS, Patricia Teixeira. Op cit, p. 178.
} 
ante a possibilidade de se perder de vez os convertidos para o "pernicioso ambiente" islâmico, marcado pela presença das confrarias sufis, os missionários da Nigrizia apostaram na criação de duas colônias anti-escravistas: a primeira, com o nome de Gezira e a segunda denominada Leão XIII, que perdurou no Egito até o final da Segunda Guerra Mundial.

Nessas colônias impunha-se uma rígida disciplina de controle do trabalho, onde não deveria existir espaço para o tempo ocioso. Além disso, buscava-se intervir nas relações afetivas, a fim de se incentivar matrimônios entre os catecúmenos e o surgimento de famílias cristãs desde o nascedouro. ${ }^{13}$

Contudo, não foram poucas as reações contrárias de jovens e mulheres catecúmenos que não aceitavam o controle sobre o direito de ir e vir e o fato de não poderem ter plenamente a posse dos seus sapatos, considerada símbolo máximo da autonomia. Os sacerdotes Carlo Tappi e Casemiro Giacomelli, que tiveram participação nos rumos das duas colônias, não deixavam de registrar as dificuldades geradas pela "insubordinação" e a reivindicação pela posse dos sapatos como o primeiro sinal de questionamento do controle missionário. ${ }^{14}$

Os maus exemplos das "insubmissas e desgraçadas" eram contrapostos por relatos de histórias de religiosas nativas, como Giuseppina Condè e também de uma importante religiosa da Nigrizia, que foi prisioneira dos mahdistas e que continua o seu trabalho missionário após a sua libertação, que se chamava Fortunata Quascè. ${ }^{15}$

Juntamente com a história de Fortunata Quascè, era conhecida também a história de uma jovem albina, batizada pelos missionários com o nome de Bianca Lemuna. Esta era percebida pelos catecúmenos e pelos missionários como um "ser exótico"e com conotações sobrenaturais, uma vez que os religiosos que a receberam como tutores desconheciam o fato de que poderiam existir negros albinos nos anos de 1890. Bianca era apontada como um exemplo pela sua inocência, por querer estar sempre com as irmãs e por ter recusado os arranjos

${ }^{13}$ SCHERMANN, Patricia Santos.Op cit, cap. 04 e RENAULT, François. Lavigerie, $l$ ' ésclavage africain e l'Europe. Tome II-Campagne antiescalvagiste. Paris, Éditions E. de Boccard, 1971.

${ }^{14}$ Idem, cap. 03 e 04.

${ }^{15}$ Idem, Pp. 300-350. 
matrimoniais do general britânico Charles Gordon, governandor geral do Sudão, com jovens da mesma "natureza exótica" de Bianca. ${ }^{16}$

Um dos exemplos destacados pelos missionários da Nigrizia da humildade "natural" de Bianca, foi o episódio em que ela poderia escolher entre um pão preto e um pão branco para comer e Bianca opta pelo pão preto, dizendo que como era diferente das Irmãs, ela deveria deixar o pão "mais claro" para elas e o mais "escurecido" para si mesma. ${ }^{17}$

Há quantos anos temos na missão católica de El-Obeid, capital do Cordofan, uma menina de cerca de quinze anos, de cor branco-avermelhada nascida de pais negros, da qual creio interessantíssimo fazer um sinal, seja pelo fenômeno extraordinário da anomalia de sua cor, seja pela sua qualidade moral, entre as quais resplandecem uma singular piedade, uma integridade e retidão de costumes verdadeiramente admiráveis, com um especial fervor para com a nossa Santa Religião, de comparar-se com os primeiros cristãos do tempo dos apóstolos.

O nome primitivo daquela jovem é Lemuna. Mas como nós damos aos nossos convertidos um nome cristão, fazendo servir o nome primitivo como sobrenome, e como foi imposto o nome de Bianca no Santo Batismo administrado no dia 7 de junho de 1879 pelo Reverendíssimo D. Battista Fracaro, Superior das Missões Católicas do Cordofan, assim ela se chama Bianca Lemuna.

(...) Seu pai que tem por nome Ninghina é de cor negra, sua mãe que tem por nome Gen-tid é também de cor negro-etíope e as irmãs que diz ter, uma é perfeitamente negra e a outra é vermelha, mas tende à cor dos abissínios. Seu pai Ninghina é um dos mais ferozes e enraivecidos jialaba ou negreiro, que se enriquece com o sangue dos pobres escravos, roubando da sua pátria e entregando-os a outros jialabas. Enquanto estava ocupado com a caça dos escravos em uma terra longe da sua, a nossa Bianca veio a ser raptada junto com a sua escrava por um bando de negreiros traficantes de carne humana. (...) Foi então presenteada como um interessante presente ao Senhor Gordon Paxá, governador geral do Sudão, o qual, passando

\footnotetext{
${ }^{16}$ Idem. p. 318 .

${ }^{17}$ Idem. p. 318 .
} 
por El-Obeid, teve o nobre pensamento de dá-la à nossa Missão do Cordofan para ser cristã e assegurar o seu futuro.

(...) Bianca apenas ingressou na nossa missão e foi instruída nas máximas da nossa Santa Religião por uma jovem religiosa oriental da Província de Damasco chamada Virgínia Mansur e teve por mestra a negrinha Fortunata Quascè, proveniente do Gebel-Nuba, e por ora é noviça do instituto das irmãs e que continua a sua instrução. Desde o dia no qual Bianca conheceu a nossa Santa Fé tornou-se uma fervorosa católica.

(...) Fortunata Quascè, sua mestra, convidou-a muitas vezes para comer o pão branco das Irmãs, que é de frumento, porém muito inferior aos nossos pães na Europa, mas Bianca recusou-o sempre dizendo: 'não é conveniente que eu, uma pobre escrava, coma o pão das Irmãs que são livres'. Há quem observe que ela no momento do batismo se tornou livre como as irmãs, porém ela disse: 'é verdade que agora sou cristã, mas eu nasci escrava e não é conveniente que eu coma o pão das irmãs que nasceram livres e que sempre foram cristãs; por mim convém comer o pão dos negros e eu sou feliz e bem aventurada por ser a serva das Irmãs. ${ }^{18}$

Além de Bianca Lemuna, ganhou destaque nesse período do controle mahdista do Sudão, a história de uma jovem escrava que fora batizada como Josephina Bakhita. Como já foi dito, Bakhita veio a ser canonizada em 2002 pelas razões que tornaram Giuseppina, Fortunata e Bianca exemplos: a noção de uma religião "inata" e os valores da "docilidade", da "obediência" e da "gentileza".

Bakhita, de acordo com Ida Zanollini, teria nascido por volta de $1880 \mathrm{em}$ Olgossa no Sudão e passara por vários donos até ser vendida para o cônsul italiano Calisto Legnani.

O mesmo a confiara a uma das famílias de comerciantes italianos, cuja esposa queria uma babá para sua filhinha. Dado o desejo da mãe de que a criança fosse educada na Europa, a Sra. Michelle levou Bakhita e sua filha para Veneza, confiando-as aos cuidados das Religiosas Canossianas, onde permaneceram por ocasião do retorno da mãe da menina para o Sudão.

\footnotetext{
${ }^{18}$ COMBONI, Daniele. Bianca Lemuna ossia una ragazza bianca-rossa nata dei genitori negri, In: Annali del Buon Pastore. Verona, 1881 fascícolo 25 pp. 36-44, apud SCHERMANN, Patricia Santos. Op cit, pp.186-187.
} 
No convento com as Irmãs, Bakhita se convertera ao Catolicismo e quando solicitada para voltar ao Sudão, alguns anos mais tarde pela Sra. Michelle, a jovem foi tomada pela "força do Espírito", segundo Zanollini, fazendo ela relutar em seguir com sua senhora. Sua história tornou-se conhecida e acabou por envolver o Patriarca de Veneza que deliberou que Bakhita deveria permanecer na Itália, uma vez que no país não havia escravidão. Contudo, ela deveria ficar confiada aos cuidados das irmãs.

Posteriormente, Bakhita ingressou para a vida religiosa e foi destinada para a casa das Canoissianas em Schio no Veneto, onde permaneceu até sua morte em 1947.

Na construção hagiográfica sobre Bakhita que deu argumento para seu processo de canonização, apontou-se que a mesma enquanto escrava e posteriormente como livre, sabia respeitar seus superiores e que chamava a Deus de "Paron". De acordo com Zanini, comentando o depoimento de Bakhita para uma das religiosas canossianas:

O Paron. Exatamente como os patrões que ela teve enquanto foi escrava. Um Senhor a quem sempre se deve obedecer com solicitude, mas não por obrigação, nem por constrangimento, mas porque a "obediência agrada tanto ao Senhor... Como escravos era preciso obedecer pela força, senão, voavam chibatadas e eram muitas! Agora, obedecemos com alegria... e quando estou com ele, e onde ele quer, estou bem em qualquer lugar. Ele é o Senhor, eu sou a sua pobre criatura" ( trecho do depoimento de Bakhita). Um Senhor bondoso, que nunca deixa o seu servo sozinho, mas guia-o a cada momento da vida. "Eu dou tudo ao Paron e ele vai cuidar de mim; é obrigado a fazer isso" (novamente a citando). Um patrão exigente, mas caridoso, pronto a suprir as necessidades de quem o serve com amor. Assim, a uma pessoa que, com um pouco de superficialidade, se espanta pelo fato de ela sempre conseguir fazer a vontade de Deus com alegria e sem nunca mostrar cansaço, Bakhita responde: "Acha que é fácil contentar o Patrão? Mas eu faço tudo o que posso. Ele faz o resto. ${ }^{19}$

${ }^{19}$ ZANINI, Roberto. Op cit, pp. 20-21. 
Por essa forma de se construir a trajetória de Bakhita, percebe-se que a jovem resgatada trouxe para sua vida religiosa os padrões de comportamento e a hierarquia de papéis vivenciada na sua condição de escrava. Contudo, nesse relato e na obra de Zanollini, bem como no primeiro manuscrito ditado por Bakhita em 1923, percebe-se que, de um lado, ela aponta a submissão ao Deus como seu Senhor e nessa margem de ações que ela desenvolve de subalternidade, exige, dentro do campo do costume, seus direitos conquistados no cotidiano numa relação direta com o seu Paron e com as representantes dele na Terra, no caso as religiosas Canossianas. Tal relato, somado ao momento em que Bakhita se posiciona em querer ficar na Europa, foi visto pelos seus hagiógrafos como um arroubo de espírito e não como uma resistência consciente da personagem às condições que a aguardavam no retorno ao Sudão e, ao mesmo tempo, um apelo ao atendimento das suas revindicações, embasada no direito adquirido por ser uma boa serva. ${ }^{20}$

Bakhita foi canonizada como a santa da África contemporânea, como a "grande Irmã Universal" e, tais aspectos nos remetem para as ressignificações de antigas práticas subalternizantes das mulheres africanas, já no contexto pós colonial, onde a necessidade de controle do corpo das africanas se coloca ainda como condição sine qua non para o enraízamento do Cristianismo no continente.

Essa pesquisa sobre a ressignificação dos mecanismos subalternizantes da mulher africana se entrelaça com os rumos do destaque ao papel da mulher contemporânea na família cristã, tal qual imaginada no papado de João Paulo II. Esta seria a guardiã dos filhos, baluarte da fé e santuário doméstico face à um mundo cada vez mais desafiador e emergente de 'novas vozes' e 'rostos' que, devido ao fenômeno contemporâneo da imigração proveniente de países da África e da Ásia para a Europa, transformam o panorama cultural, político e religioso da "Velha Europa".

Este artigo tem, por fim, o objetivo de apontar como o estudo dos mecanismos contemporâneos de subalternização da mulher negra africana, a partir do passado da experiência das "resgatadas da escravidão" precisa cada vez mais analisado e dimensionado a luz também da inserção subalterna dos países da África no processo de Globalização.

\footnotetext{
${ }^{20}$ PINHEIRO, Cláudio Costa. No governo dos mundos: escravidão, contextos coloniais e administração de populações, In: Estudos Afro-Asiáticos, ano 24 n.03, 2002. e LABANCA, Nicola. Il razzismo coloniale italiano, In: BURGIO, Alberto. Nel nome della razza: il razzismo nella storia d'Italia - 1870-1945. Bologna,: Il Mulino, 2000.
} 